\title{
Community-based Decision Making in Japan
}

\author{
Norio Okada · Liping Fang · D. Marc Kilgour
}

Published online: 23 October 2012

(C) Springer Science+Business Media Dordrecht 2012

\begin{abstract}
An overview of participatory community-based decision systems in Japan is presented. In this disaster-prone country, effective community coping capacity has developed, largely to fill community-level needs for disaster preparation, mitigation, and response. Experience with three concepts of disaster planning and management, namely "Kyojo" (Neighborhood or Community Self-Reliance), "Jijo" (Individual or Household Self-Reliance), and "Kojo" (Government Assistance), is recounted and assessed. Then three structures for disaster management, Jiishu-bosai-soshiki (Selfsupport Disaster Reduction Association), "Machizukuri" (citizen-led town-creation), and "Toshikeikaku" (urban or city planning), are discussed. Finally, the contributions of the three papers in this special issue are related to Japanese community practices and to the broader perspective of group decision and negotiation.
\end{abstract}

Keywords Community-based decision making · Disaster culture · Disaster management · Group decision support systems · Japan ·

Participatory decision making

\footnotetext{
N. Okada

Graduate School of Science and Technology, Kumamoto University, Kumamoto, Japan e-mail: n-okada@kumamoto-u.ac.jp

L. Fang

Department of Mechanical and Industrial Engineering, Ryerson University,

Toronto, ON, Canada

e-mail: 1fang@ryerson.ca

D. M. Kilgour $(\varangle)$

Department of Mathematics, Wilfrid Laurier University, Waterloo, ON N2L 3C5, Canada

e-mail: mkilgour@wlu.ca
} 


\section{Introduction}

As a field of study, Group Decision and Negotiation has maintained a focus on the creation of structures within which negotiation is feasible, rather than on the negotiated decisions themselves. For example, many computer-based systems have been designed to encourage communication within a group and to facilitate group decision processes. For a discussion of the role of group decision support systems, see the articles by Ackermann and Eden (2010), Vogel and Coombes (2010), and others in the Handbook of Group Decision and Negotiation (Kilgour and Eden 2010).

Carefully designed group support systems, sometimes with human facilitators and sometimes without, can enable individuals with diverse viewpoints and roles to reach agreements on difficult issues, and - when the highest level of success is achieved-to develop a shared understanding of an organization's mission. For some groups, it is a great achievement to develop understanding of how members can contribute to a solution, and to establish a language that enables them to communicate effectively as they implement the solution. These systems are designed to be applied within an existing organization, or within a few existing organizations that find themselves compelled to cooperate.

The subject of this special issue is the development, within a natural context, of systems that achieve many of these same objectives. Japan is a country with a high frequency of natural disasters (see, for instance, CRED 2012), and a substantial rural population that is often isolated and threatened by challenges such as the Great East Japan Earthquake (Higashinippon Dai-Shinsai) of March 11 2011. In response to these grave risks, many community-based systems have been developed to regulate, coordinate, and improve responses to threats at the community level.

Within this special issue, we will describe the organization of some of these systems, and ways that have been suggested to improve them further. We believe that community-based decision making in Japan is an important model for decision processes everywhere, and that researchers and others will be well-served by understanding and emulating that model.

\section{Japan's “Disaster Culture”: A Cooperation/Collaboration Society}

At the end of every year, a Japanese non-profit organization, whose main role is to certify literacy levels in Chinese characters, conducts a survey to identify the Chinese character that is most appropriate to represent the events of the previous year and their implications. In 2011, the year of the Great East Japan Earthquake Disaster, approximately 500,000 votes were cast; the Chinese character 絆 , "KIZUNA," meaning "bonds" or "ties among individuals," was the winner (Japan Society for the Examination of Chinese Literacy Levels 2011).

In fact, the focus on cooperation is not surprising. There is convincing evidence (Dentsu Inc. 2011; JTB Comprehensive Research Institute 2012) that after large-scale disasters many Japanese, especially younger people, place higher values on family bonds, cooperation and collaboration at the family and community levels, and provision of help to disaster-ravaged communities. In contrast, prior to the disaster attitudes 
later described as "excessive competition", engagement in a "win or lose game," and immersion in "nihilism," were common. Further evidence of this trend, both concrete and symbolic, comes from an internet survey about changes in social attitudes (DIMSDRIVE Inc. 2012). Among those who live alone, almost $50 \%$ reported that they are now thinking about getting married or finding a partner-a boyfriend or girlfriend.

This new attitude is often seen as a socio-cultural and socio-psychological consequence of the disaster of March 11, 2011. Another interpretation is that it is simply attributable to the "disaster culture" (Button 2010) that Japan has developed, almost as a hidden cultural gene. During this disaster, many villages and towns demonstrated effective community coping capacity, surprising many who had believed that cooperative and collaborative power had weakened over the years, reflecting not only increasing modernization and urbanization, but also rural population decline.

Sankei Sinbun (2011), a national newspaper, reported that, only three weeks after the Great East Japan Earthquake Disaster, the stricken isolated community of Minami Sanriku-Cho, Miyagi Prefecture, had implemented a program to divide scarce foodstuffs among all households. The villagers explained that, based on a relationship of trust, they were honoring each other by enabling their village to work at maximum strength.

CNN (2011) reports also confirm Japan's community-rooted sense of order, a cultural characteristic that becomes active during times of extreme stress. It was noted that one layer of human turmoil-the looting and scuffling for food or services that often follows a disaster-is noticeably absent in Japan:

"Looting simply does not take place in Japan. I'm not even sure if there's a word for it that is as clear in its implications as when we hear 'looting,"' said Gregory Pflugfelder, director of the Donald Keene Center of Japanese Culture at Columbia University. Japanese have "a sense of being first and foremost responsible to the community," he said.

In fact, the ability of Japan's traditional neighborhood communities to cope with crises is so well-established that it is natural to ask whether they function only during or after a disaster.

The answer is "No." Japan's sense of community organization facilitates cooperation and collaboration even in normal (non-disaster) times. In particular, the tradition of cooperation and collaboration for disaster reduction at the community level has been applied not only to disaster response, but also to disaster preparation and mitigation. This Special Issue focuses on attempts to understand this impressive cultural phenomenon, and suggest ways to reinforce it.

\section{Self-Reliance, Group-Reliance, and Assistance}

To understand disaster planning and management in Japan, one must understand the contrast among "Kyojo" (Neighborhood or Community Self-Reliance), "Jijo" (Individual or Household Self-Reliance), and "Kojo" (Government Assistance). As Fig. 1 illustrates, these concepts overlap. Japan is doing its best to increase both Kyojo and Jijo self-reliance roles, and to depend less on Kojo, which in the past was the major agent to mitigate disaster. 
Fig. 1 Three types of assistance for disaster risk reduction

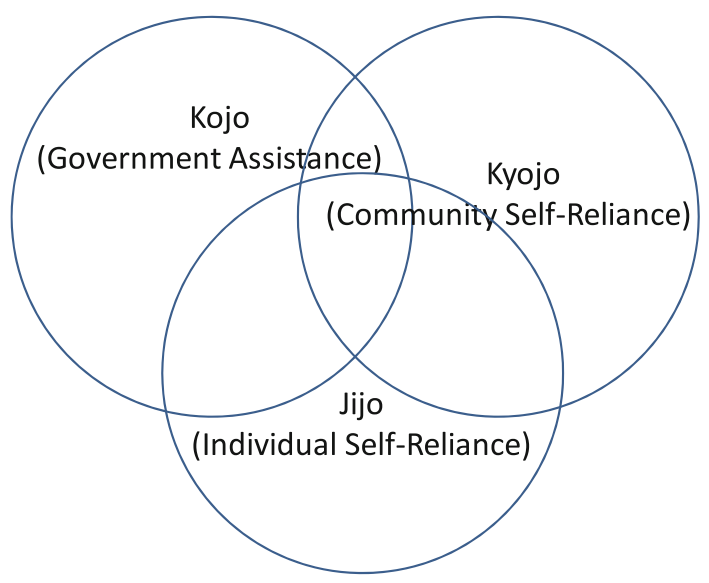

Table 1 Conventional disaster planning versus twenty-first century integrated disaster risk management (based on Okada 2006)

\begin{tabular}{ll}
\hline Twentieth century & Twenty-first century \\
\hline Reactive & More proactive \\
Focus on emergency response and crisis management & Focus on risk mitigation and preparedness \\
Countermeasure manual approach & More anticipatory/precautionary approach \\
Predetermined planning (non-surprise) & More comprehensive policy-bundle approach \\
Sectoral countermeasure approach & More adaptive management approach \\
Top-down & More bottom-up \\
\hline
\end{tabular}

Even though major disasters are rare, their frequency in Japan is great enough that considerable effort has applied to studying how to reduce their impacts. Japan's disaster planning and management policy changed significantly after the Great Hanshin Awaji (Kobe) Earthquake of January 17, 1995. Table 1 contrasts the approaches before and after this cataclysmic event. The current approach stresses strategies that are proactive, anticipatory, precautionary, adaptive, participatory and bottom-up. The rationale is that governments have been found to be of relatively little help immediately after a high-impact disaster. Lives in peril have been saved by the actions of the individuals themselves and their neighbors. Unfortunately, the relative lack of success of local governments in disaster reduction was again clearly evident during the 2011 Great East Japan Earthquake Disaster.

\section{Community-based Disaster Reduction: Jishu-bosai-soshiki Versus Machizukuri}

Japan has a long history of participatory community disaster risk management. Long before the 1995 Kobe earthquake disaster in Japan, community organizations known as Jiishu-bosai-soshiki (Self-support Disaster Reduction Association) flourished. Origi- 
Table 2 Machizukuri versus Toshikeikaku

\begin{tabular}{ll}
\hline Machizukuri approach & Toshikeikaku approach \\
\hline $\begin{array}{l}\text { Led by citizens. Requires } \\
\text { a local leader or } \\
\text { champion. Participatory }\end{array}$ & Led by government. Administrative and based on law \\
$\begin{array}{l}\text { May be self-financed or } \\
\text { publicly financed. }\end{array}$ & Publicly-financed. Project-based with a set time span \\
$\begin{array}{l}\text { Voluntary } \\
\text { Holistic }\end{array}$ & \\
Not necessarily space-specific & Specialized/sectionalized \\
\hline
\end{tabular}

nally their orientation was more toward post-disaster emergency management, such as rescue and relief as well as self-evacuation. After 1995, these community associations were encouraged by their local governments to improve preparedness and encourage proactive action at the community level. In a study of the roles and characteristics of these organizations, Bajek et al. (2008) concluded that they tended to be guided and mobilized by local governments, and that their aim was to supplement expected government actions, rather than to find ways reduce disaster risks in residential areas. This conclusion suggests that cultural factors may be involved in community cooperation and collaboration in Japan.

In contrast to Jiishu-bosai-soshiki, another approach to neighborhood-level disaster reduction is now more common. The "Machizukuri" (citizen-led town-creation) approach includes many local initiatives aimed at reducing disaster risks or mitigating disaster effects in a community. Okada (2012b) compares machizukuri with "toshikeikaku" (urban or city planning)—see Table 2. Machizukuri is citizen-led and non-administrative, while toshikeikaku is administrative and based on a legal framework. Both are intended to improve the common spaces where people live and work. From the viewpoint of disaster risk reduction, the difference between jiishu-bosaisoshiki community activities and the machizukuri approach is that the latter is holistic, multi-focused, and broader in scope — often not limited to "disaster concerns." Moreover machizukuri is citizen-led, involves multiple stakeholders, and takes account of day-to-day issues instead of focusing on one-time problems.

Okada (2012b) proposed systematic conceptual models for understanding the machizukuri approach. Figure 2 illustrates the multi-layer common spaces (an extension of the concept of infrastructure) for a city, region or neighborhood community as a living body (Okada 2004). In the context of this diagram, machizukuri is more appropriately applied on a neighborhood community scale, rather than on a wider scale, such as city or region. Applied to a neighborhood community in the context of a five-storied pagoda model, it starts with the fifth layer (daily life), followed by the fourth (land use and built environment), and the third (infrastructure). By comparison, toshikeikaku focuses mainly on the fourth and third layers. Another point of contrast is that machizukuri requires citizen involvement to induce attitudinal or behavioral change, while this issue is not essential for toshikeikaku.

The dynamic processes implementing such a change can be explained and systematically modeled by the nested Plan-Do-Check-Action (PDCA) cyclic structure, as 


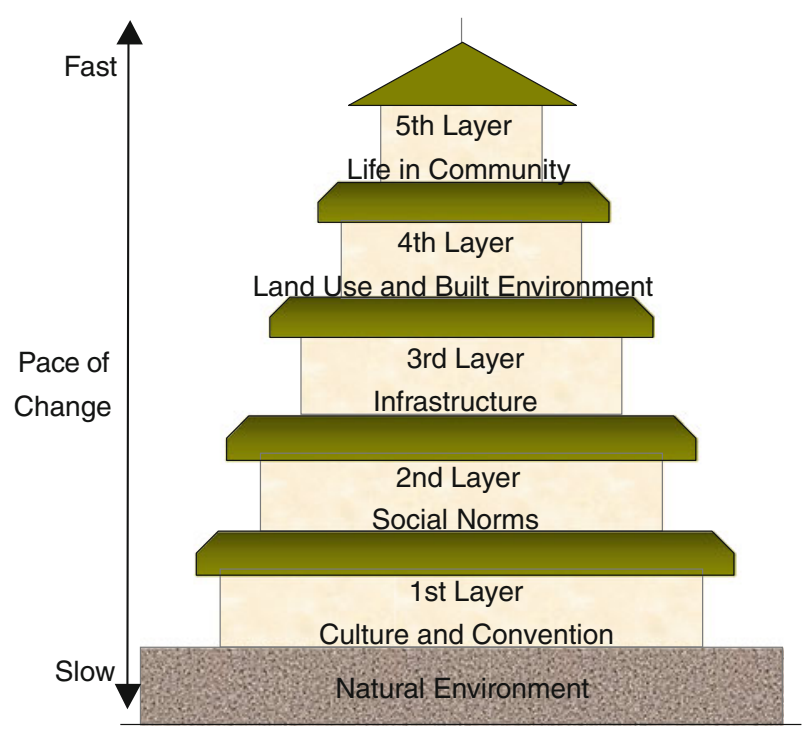

Fig. 2 Cities/regions viewed as spatial-temporal multi-layer system

Fig. 3 Nested structure of PDCA (small, medium, and large)

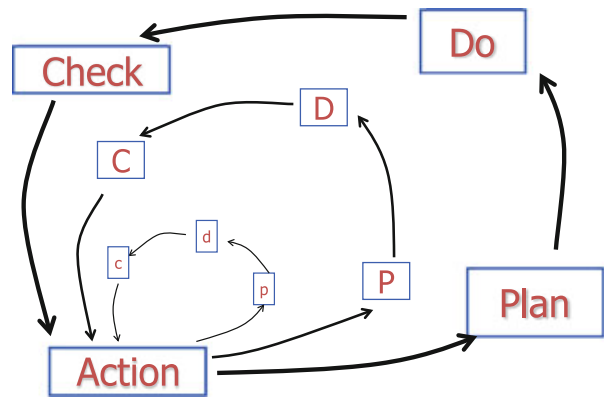

shown in Fig. 3. Okada (2012a) proposed this structure as a positive adaptive management system, and successfully applied it to various machizukuri field-based "social experiments" to change people's attitudes and actions.

\section{Overview of the Special Issue}

The above findings can be put into a group decision and negotiation perspective. Both jiishu-bosai-soshiki community activities and machizukuri for disaster risk reduction are modeled as community-based decision making systems for disaster management. They are participatory approaches for communities at risk that usually involve multiple stakeholders including individuals, households, community subgroups, non-governmental organizations (NGOs), academics and government officials.

The paper by Yamori (2012) presents a disaster prevention game called Crossroad for community-based decision making and brainstorming/image training for post- 
disaster emergency management. Crossroad incorporates dynamic processes involving experiencing and reflecting on a collection of individual-level dichotomous (Yes/No) scenarios requiring choices (decisions) for each scenario. It provides a tool for virtual learning about path-dependent, viable solutions, and encourages users to consider possible choices not taken.

A participatory method to support group decision making, the Yonmenkaigi System Method (YSM), is described by Okada et al. (2012). YSM applies to communitybased decision-making, and emphasizes social implementation for pre-disaster risk reduction. It incorporates dynamic processes to collaboratively develop implementable actions, and involves four role-playing groups. Adaptive management is achieved through win-win debating to develop a collaborative action plan. The focus is on the synergistic process of collaborative development for mutual learning, decision making and capacity building.

The paper by Sakakibara and Kimura (2012) presents an experimental study in which conflict participants' behavior was observed and assessed. Coordination through negotiation and facilitation for social development-not limited to disaster management-is investigated through the game experiment. The experiment is based on three different two-player strategic-form games, including (i) win-win, (ii) win-lose, and (iii) indifferent-win games, which themselves are to be further coordinated. The effect of negotiation and the role of the facilitator in improving coordination are studied.

\section{Conclusion}

Community-based decision making is effective even when individuals are competitive, provided that the conflict does not overwhelm their shared interests. Special situations such as disaster, crisis, accident, and community-issue management inevitably require some form of cooperative or collaborative mechanism. Because Japan has long experienced-and survived—-such crises, it has developed a significant disaster culture. Thus, Japan provides ample examples of effective community management and participatory methods to support group decision and negotiation. There is no reason for these methods to be limited to Japan; we believe that they can be tailored to other countries, especially those that are prone to similar disasters, crises, and accidents. Community-based management is needed to solve the problems of communities - an observation that is true everywhere in the world. This special issue provides readers with an opportunity to understand and appreciate community-based decision making in Japan, with its special focus on disaster management.

\section{References}

Ackermann F, Eden C (2010) The role of group decision support systems: negotiating safe energy. In: Kilgour DM, Eden C (eds) Handbook of group decision and negotiation. Springer, Dordrecht, pp 285-300

Bajek R, Matsuda Y, Okada N (2008) Japan's Jishu-bosai-soshiki community activities: analysis of its role in participatory community disaster risk management. Nat Hazards J Int Soc Prev Mitig Nat Hazards 44:281-292 
Button G (2010) Disaster culture: knowledge and uncertainty in the wake of human and environmental catastrophe. Left Coast Press, Walnut Creek

CNN (2011) Orderly disaster reaction in line with deep cultural roots. CNN, March 12, 2011, http://news. blogs.cnn.com/2011/03/12/orderly-disaster-reaction-in-line-with-deep-cultural-roots/. Accessed 20 Aug 2012

CRED (Centre for Research on the Epidemiology of Disasters) (2012) EM-DAT: the international disaster database. WHO Collaborating Centre for Research on the Epidemiology of Disasters (CRED), Universite catholique de Louvain, Brussels. Accessed 17 Sept 2012

Dentsu Inc. (2011) Dentsu attitude survey for fathers and mothers after the Great East Japan Earthquake Disaster. News Release, September 29, 2011, Dentsu Inc. http://www.dentsu.co.jp/news/release/2011/ pdf/2011113-0929.pdf. Accessed 26 Aug 2012 (in Japanese)

DIMSDRIVE Inc. (2012) Survey of people's attitudinal change one year after the Great East Japan Earthquake Disaster. March 8, 2012, DIMSDRIVE. http://www.dims.ne.jp/timelyresearch/2012/120308/. Accessed 25 Aug 2012 (in Japanese)

Japan Society for the Examination of Chinese Literacy Levels (Nohon Kanji Noryoku Kentei Kyokai) (2011) Kanji of 2011. http://www.kanken.or.jp/years_kanji/. Accessed 26 Aug 2012 (in Japanese)

JTB Comprehensive Research Institute (2012) Survey of changes in everyday life behavioral and consumption patterns after the Great East Japan Earthquake Disaster. http://www.tourism.jp/press/2012/06/ earthquake-june.php. Accessed 26 Aug 2012 (in Japanese)

Kilgour DM, Eden C (2010) Handbook of group decision and negotiation. Springer, Dordrecht

Okada N (2004) Urban diagnosis and integrated disaster risk management. J Nat Disaster Sci 26((2):49-54

Okada N (2006) Perspective on integrated disaster risk management. In: Hagihara Y, Okada N, Tatano H (eds) Introduction to integrated disaster risk management. Kyoto University Academic Press, Kyoto, pp 9-54 (in Japanese)

Okada N (2012a) Adaptive management planning with a focus on participatory planning. UNU-CECAR 2012 Courses, Tokyo, March 7, 2012

Okada N (2012b) Lessons learned from recent disasters in Japan, and implications for ASEAN countries. Keynote presentation at ASEAN-Japan meeting, 26 June, Naha

Okada N, Na J, Fang, L, Teratani A (2012) The Yonmrnkaigi System Method: an implementation-oriented group decision support approach. Group Decis Negot. doi:10.1007/s10726-012-9307-5

Sakakibara H, Kimura K (2012) Experimental study on negotiation process in participatory decision making process in a community. Group Decis Negot. doi:10.1007/s10726-011-9268-0

Sankei Sinbun (2011) Food almost used up, yet dividing based on trust, people helping each other by staying in their own damaged homes: news from Minami Sanriku-Cho, Miyagi Prefecture. Sankei Sinbun, April 4, 2011. http://sankei.jp.msn.com/life/news/110404/trd11040410550007-n1.htm. Accessed 25 Aug 2012 (in Japanese)

Vogel D, Coombes J (2010) The effect of structure on convergence activities using group support systems. In: Kilgour DM, Eden C (eds) Handbook of group decision and negotiation. Springer, Dordrecht, pp 301-312

Yamori K (2012) Using games in community disaster prevention exercises. Group Decis Negot. doi:10. 1007/s10726-012-9307-5 